\title{
Organizing, supporting and linking the world marine biodiversity research community
}

Submitted 16 November 2014; accepted 20 November 2014; first published online 10 February 2015

How well-organized and informed is the marine biology and biodiversity research community internationally? Understanding marine biodiversity and the functional attributes of diverse marine systems demands integration and collaboration across disciplines. The recent 10-year Census of Marine Life was a significant advance, bringing together thousands of researchers to collaborate at unprecedented regional to global scales (Costello et al., 2010). The Global Ocean Biodiversity Initiative began in 2008 and focuses on the open ocean and the deep sea. At the same time Europe funded the Marine Biodiversity and Ecosystem Function (MarBEF) network of excellence, another large and influential grouping of marine scientists. Both organizations took part in the first World Conference of Marine Biodiversity, organized by MarBEF, that established the WCMB series in 2008 and provided marine researchers with a regular forum for exchange. A recurring theme in many of the keynote presentations at the 3 rd WCMB held last October in Qingdao (Figure 1) was the value and insights from collaborative international research. For example: Angelika Brandt described exciting discoveries of deep-sea diversity and productivity in the Kurile Kamchatka Trench by joint German and Russian cruises; Suchana Apple Chavanich reviewed the state of marine biodiversity in the Western Pacific (SE Asia) following disturbances ranging from over-fishing to tsunami events, and how new international scientific programmes are leading research in the region; Sun Song described the climate change factors influencing the structure and function of marine ecosystems, using examples of jellyfish blooms near Qingdao which may provide a template for how such blooms occur elsewhere in the world; Graham Edgar summarized some of the analyses from a replicated global survey of over 2400 sites through collaboration with citizen scientists in the Reef Life Survey programme; Emmett Duffy introduced approaches to develop methods for monitoring ecological interactions that can be replicated globally; Mark Costello illustrated insights from using global species databases to see trends in taxonomic discovery and biogeographic patterns in species richness, including latitudinal gradients, involving over 65000 species; and John Gunn presented recent efforts to define 'essential ocean variables' that could be a basis for monitoring trends in the oceans at global scales, and the need for a top-down approach to their definition. Evidently there is increasing research happening at global as well as local scales in marine biology.

Following on from the Life in a Changing Ocean theme of the $3 \mathrm{rd} \mathrm{WCMB}$, the theme selected for the 4 th WCMB is Connecting with the Living Ocean, underlining the need to replace our current exploitation relationship with the ocean's living resources, with a sustainable connection based on scientific knowledge. This theme will be particularly topical as the 4th WCMB will be held 2 years before the end of the United Nations Decade on Biodiversity 2011-2020 (Resolution 65/161), providing an opportunity to discuss the 2020 Aichi Biodiversity Targets. With the unprecedented change in polar regions and locations near the Canadian Arctic, polar biodiversity will be one of the theme sessions. A second major theme will be an innovative virtual laboratory session in collaboration with Ocean Network Canada (oceannetworks.ca). We will connect participants attending the 4 th WCMB with live imagery and data feeds from a network of cabled seafloor observatories located more than $3800 \mathrm{~km}$ from Montreal and up to $300 \mathrm{~km}$ off the west coast of Canada, at depths down to $2700 \mathrm{~m}$. During the opening virtual laboratory session, all conference participants will be invited, along with media and the general public to showcase how new technology is making the ocean accessible from everywhere, and to visually reinforce the connection of marine biodiversity and related ecosystem services to human society. The 4th WCMB (http://wcmb2018.org/) will highlight the global importance of the ocean and its many forms of life. Together, they are an integral part of the support system that sustains our planet. During the conference in Montreal, home of the CBD Secretariat (co-chair of the organizing committee), it will explicitly encourage inter-disciplinary discussions and the use of novel technologies and social media to involve researchers, policy makers, NGOs, industry and students in 'Connecting with the Living Ocean'.

From its beginning in 2008 , the WCMB has provided a forum for scientists to meet and has demonstrated the solid foundation of international collaboration and research networks in marine biodiversity (Miloslavich \& Klein, 2009). 


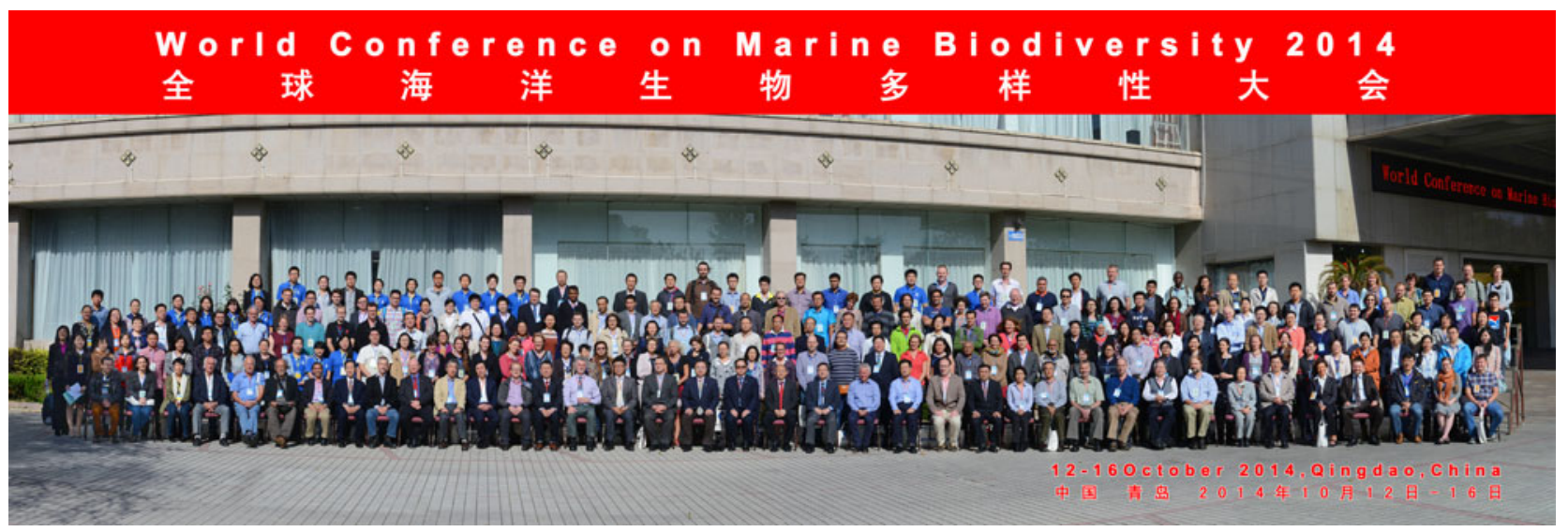

Fig. 1. Delegates at the 3rd World conference on Marine Biodiversity in Qingdao, China, 14 October 2014.

This community has strengthened since then and may wish to maintain better mechanisms of communication between meetings. The Intergovernmental Oceanographic Commission provides a global forum for government marine science agencies, and the World Association of Marine Stations aims to do so for institutes, but there is currently no active global forum for marine biodiversity scientists.

The International Association for Biological Oceanography (IABO, http://www.iabo.org) provides a forum for individual marine biologists as members. It was established in 1964 under the aegis of the International Union of Biological Sciences (IUBS) to promote the advancement of a unified biological knowledge platform by providing opportunities for communication between marine biologists and other sciences. IABO is formally represented on the SCOR Executive Committee, and a member of IUBS and thus the International Council of Scientific Unions (ICSU). Its sister organization is the International Association of Physical Ocean Sciences (IAPSO). IABO has an email list of over 800 subscribers from over 40 countries called 'MARINE-B' (MArine Research Information NEtwork on Biodiversity, https://listserv.heanet.ie/marine-b.html). However, until now, IABO's membership constituted representatives nominated by national academies. For some years this has proved unsatisfactory and IABO has had a low profile amongst its community.

A variety of international initiatives need involvement of marine biodiversity scientists, including the International Panel on Biodiversity and Ecosystem Services (IPBES), UN World Ocean Assessment, Group on Earth Observations Biodiversity Observation Network (GEO BON), Future Earth (of the International Council of Scientific Unions), the Circumpolar Biodiversity Monitoring Program's Marine Conservation of Arctic Flora and Fauna Working Group, and Convention on Biological Diversity. IABO may be able to assist such initiatives in finding suitable marine biodiversity expertise, and aid its members in becoming involved in such high-profile activities. This action is especially important in initiatives that are not specifically marine, as for example IPBES, where there is a severe shortage of participation from marine biodiversity scientists in the structure and in the working groups. The pro-active identification and contacting of the relevant experts can be an important contribution from an international organization such as IABO. The establishment of the World Association of Marine Stations in 2010
(WAMS; http://www.marsnetwork.org/world-associationmarine-stations-wams) will also provide a focal point for marine biodiversity scientists since among its planned activities is to coordinate training and education in biodiversity courses located at marine stations around the world. In addition it plans to 'host' a data portal for data on marine ecosystem biodiversity indicators, time series and monitoring data.

At the recent World Conference on Marine Biodiversity IABO proposed to become a more inclusive network by expanding its Executive Committee and contacting delegates to engage them in further communication and activities. These activities would include developing an email list of interested scientists, working to support the next WCMB, endorsing scientific meetings and training workshops, aiding international initiatives in finding suitable representatives from the marine biodiversity community, ensuring close engagement with SCOR (including review of SCOR Working Group proposals) and IUBS, creating a list of related national and regional organizations, exploring ways to raise support for coordination, and reviewing the governance and statutes of IABO. For example, through IABO, SCOR provided travel grants to 10 delegates from developing countries to attend the conference. With committed members, IABO may be able to facilitate more support for marine biologists from developing countries to participate in international meetings and programmes. A particular focus of IUBS at present is to counteract the fragmentation of biology into specializations that are unaware of what they have in common. IABO could promote closer communication between sub-disciplines. Suggestions from individuals and projects that would be able to contribute to IABO activities are invited.

The WCMB series was first established by the late Carlo Heip as part of the MarBEF project (Herman, 2013). Carlo was an inspiring leader for marine biodiversity science and was responsible for very important initiatives, including MarBEF, that brought together the European scientists in this field. He also had a key role in initiatives at the global level as the Census of Marine Life, GEO BON and Diversitas. In his memory, IABO will establish a Carlo Heip Memorial Medal. The recipient will be a keynote speaker at the next WCMB. A call for nominations will be issued in 2015, and the first medal will be delivered at the next WCMB 2018 in Montreal in Canada. 


\section{REFERENCES}

Costello M.J., Coll M., Danovaro R., Halpin P., Ojaveer H. and Miloslavich P. (2010) A census of marine biodiversity knowledge, resources and future challenges. PLoS ONE 5(8), e12110. doi: 10.1371/journal.pone. 0012110.

Herman P. (2013) Obituary: Carlo Heip (1945-2013). Scientia Marina (Barc.) 77, 201-202. hdl.handle.net/10.3989/scimar.03840.05A.

and

Miloslavich P. and Klein E. (2009) The World Conference on Marine Biodiversity: current global trends in marine biodiversity research Marine Biodiversity 39, 147-152. doi: 10.1007/s12526-009-0011-x.

\section{Correspondence should be addressed to:}

M. Thorndyke

Royal Swedish Academy of Sciences \& Göteborg University, Göteborg, Sweden

email: Mike.Thorndyke@bioenv.gu.se

Mark J. Costello ${ }^{1}$, Philippe Archambault ${ }^{2}$, Suchana Chavanich ${ }^{3}$, Patricia Miloslavich ${ }^{4}$, David M. Paterson ${ }^{5}$, Siew-Moi Phang ${ }^{6}$, Isabel Sousa Pinto ${ }^{7}$, Annelies Pierrot-Bults ${ }^{8}$, Sun Song ${ }^{9}$, Eulogio H. Soto ${ }^{10}$, Nils Chr. Stenseth ${ }^{11}$, Tina N. Molodtsova ${ }^{12}$ and Michael Thorndyke ${ }^{13}$
${ }^{1}$ Institute of Marine Science, University of Auckland, Auckland 1142, New Zealand, ${ }^{2}$ Institut des sciences de la mer (ISMER), Université du Québec à Rimouski, Rimouski, Québec, Canada, ${ }^{3}$ Department of Marine Science, Faculty of Science, Chulalongkorn University, Bangkok 10330, Thailand, ${ }^{4}$ Departamento de Estudios Ambientales, Universidad Simón Bolívar, Caracas 1080, Venezuela, ${ }^{5}$ School of Biology, Scottish Oceans Institute, University of St Andrews, St Andrews KY16 8LB, UK, ${ }^{6}$ Institute of Ocean and Earth Sciences (IOES), University of Malaya, 50603 Kuala Lumpur, Malaysia, ${ }^{7}$ Centre for Marine and Environmental Research, University of Porto, R. dos Bragas 289, Porto, Portugal, ${ }^{8}$ Institute for Biodiversity and Ecosystem Dynamics (IBED) University of Amsterdam, P.O. Box 94248, 1090 GE Amsterdam, the Netherlands, ${ }^{9}$ Institute of Oceanology, Chinese Academy of Sciences, 7 Nanhai Road, Qingdao 266071, China, ${ }^{10}$ Facultad de Ciencias del Mar y de Recursos Naturales, Universidad de Valparaiso, Av. Borgoño 16344 Reñaca, Viña del Mar, Chile, ${ }^{11}$ Department of Biosciences, Centre for Ecological and Evolutionary Synthesis (CEES), University of Oslo, PO Box 1066, Blindern, 0316 Oslo, Norway, ${ }^{12}$ P.P. Shirshov Institute of Oceanology RAS, 36 Nakhimovsky prt, 117977 Moscow, Russia, ${ }^{13}$ Royal Swedish Academy of Sciences \& Göteborg University, Göteborg, Sweden 